\title{
Papain, a Plant Enzyme of Biological Importance: A Review
}

\author{
Ezekiel Amri and Florence Mamboya \\ Department of Science and Laboratory Technology, \\ Dar es Salaam Institute of Technology (DIT), P. O. Box 2958, Dar es Salaam, Tanzania
}

Received 2012-05-13; Revised 2012-05-20; Accepted 2012-06-02

\begin{abstract}
Papain is a plant proteolytic enzyme for the cysteine proteinase family cysteine protease enzyme in which enormous progress has been made to understand its functions. Papain is found naturally in papaya (Carica papaya L.) manufactured from the latex of raw papaya fruits. The enzyme is able to break down organic molecules made of amino acids, known as polypeptides and thus plays a crucial role in diverse biological processes in physiological and pathological states, drug designs, industrial uses such as meat tenderizers and pharmaceutical preparations. The unique structure of papain gives it the functionality that helps elucidate how proteolytic enzymes work and also makes it valuable for a variety of purposes. In the present review, its biological importance, properties and structural features that are important to an understanding of their biological function are presented. Its potential for production and market opportunities are also discussed.
\end{abstract}

Keywords: Proteolytic enzyme, cysteine protease, papain, structure, hydrophobic

\section{INTRODUCTION}

Papain (EC 3.4.22.2) is an endolytic plant cysteine protease enzyme which is isolated from papaya (Carica papaya L.) latex. Papain is obtained by cutting the skin of the unripe papaya and then collecting and drying the latex which flows from the cut. The greener the fruit, more active is the papain. Papain enzyme belongs to the papain superfamily, as a proteolytic enzyme, papain is of crucial importance in many vital biological processes in all living organisms (Tsuge et al., 1999). Papain shows extensive proteolytic activity towards proteins, shortchain peptides, amino acid esters and amide links and is applied extensively in the fields of food and medicine (Uhlig, 1998). It preferentially cleaves peptide bonds involving basic amino acids, particularly arginine, lysine and residues following phenylalanine (Menard et al., 1990). The unique structure of papain gives its functionality that helps to understand how this proteolytic enzyme works and it's useful for a variety of purposes. This review addresses structural features of enzyme, the biological importance and processes in which papain participates and its potential for production market opportunities.

\subsection{Properties, Structure and Features of Papain}

The globular protein, the papain PDB accession number $1 \mathrm{CVZ}$ is a single chain protein with molecular weight of 23,406 DA and consists of 212 amino acid with four disulfide bridges and catalytically important residues in the following positions Gln19, Cys25, His 158 and His159 (Mitchel et al., 1970; Robert et al., 1974; Tsuge et al., 1999). The graphical representation of the amino acid composition of papain is shown in Fig. 1. Papain is a cysteine hydrolase that is stable and active under a wide range of conditions. It is very stable even at elevated temperatures (Cohen et al., 1986). Papain is unusually defiant to high concentrations of denaturing agents, such as, $8 \mathrm{M}$ urea or organic solvent like $70 \%$ EtOH. Optimum $\mathrm{pH}$ for activity of papain is in the range of 3.0-9.0 which varies with different substrate (Edwin and Jagannadham, 2000; Ghosh, 2005).

Papain enzyme as cysteine proteases in papain superfamily is usually consisting of two well-defined domains which provide an excellent system for studies in understanding the folding-unfolding behavior of proteins (Edwin et al., 2002). 


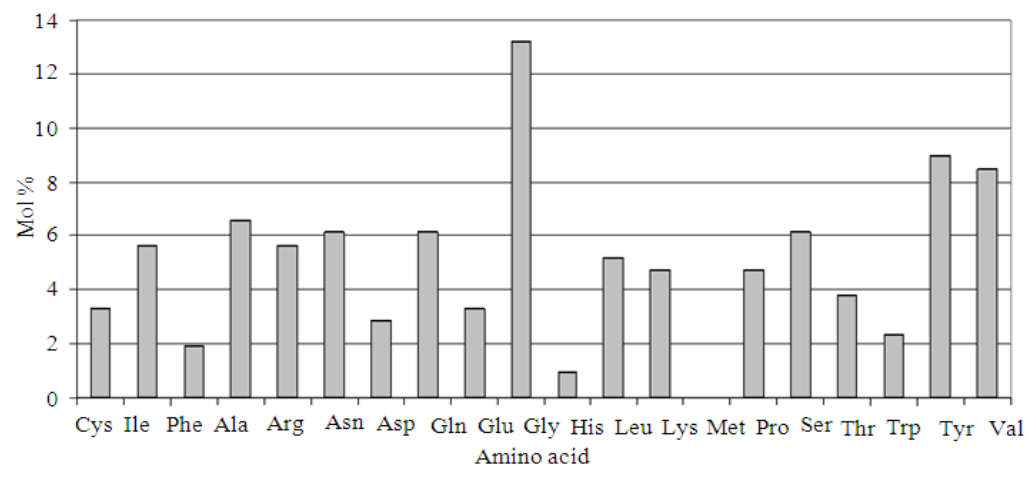

Fig. 1. Graphical representation of the amino acid composition of papain

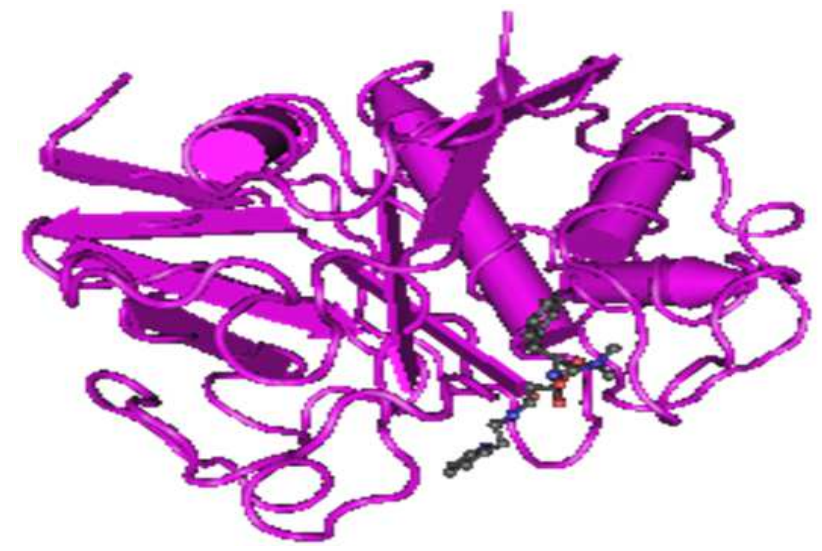

Fig. 2. Papain structure (MMDB protein structure summary, 1CVZ)

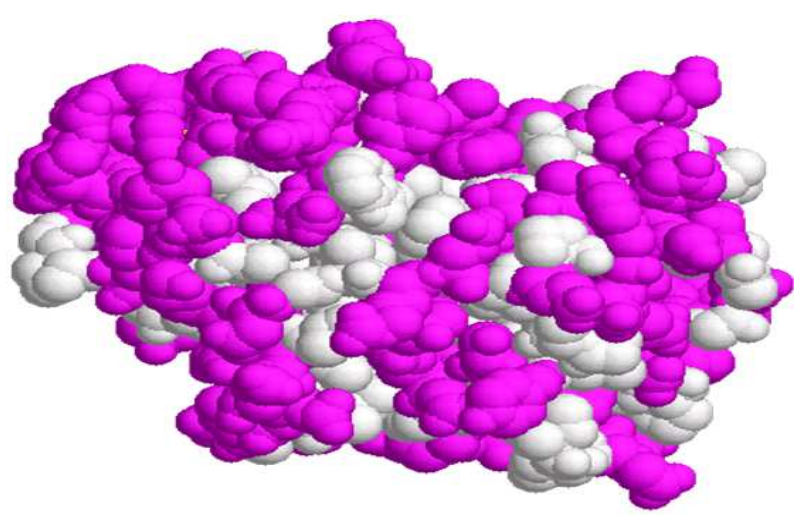

Fig. 3. Hydrophobic amino acid of papain (1CVZ). Colored gray in a space fill model are the backbone oxygen and nitrogen of the residues with the hydrophobic side chain (Source: http://www.oocities.org/bramsugar/intro4.html).
The protein is stabilized by three disulfide bridges in which the molecule is folded along these bridges creating a strong interaction among the side chains which contributes to the stability of the enzyme (Edwin and Jagannadham, 2000; Tsuge et al., 1999). Its three-dimensional structure consists of two distinct structural domains with a cleft between them. This cleft contains the active site, which contains a catalytic diad that has been likened to the catalytic triad of chymotrypsin. The catalytic diad is made up of the amino acids-cysteine-25 (from which it gets its classification) and histidine-159. Aspartate-158 was thought to play a role analogous to the role of aspartate in the serine protease catalytic triad, but that has since then been disproved (Menard et al., 1990).

Papain molecule has an all- $\alpha$ domain and an antparallel $\beta$-sheet domain (Kamphuis et al., 1984; Madej et al., 2012). The conformational behavior of papain in aqueous solution has been investigated in the presence of SDS and reported to show high $\alpha$-helical content and unfolded structure of papain in the presence of SDS is due to strong electrostatic repulsion (Huet et al., 2006). In the molten globule state ( $\mathrm{pH} 2.0$ ), papain show evidence of substantial secondary structure as $\beta$-sheet and is relatively less denatured compared to $6 \mathrm{M}$ Guanidium Hydroc8hloride $(\mathrm{GnHCl})$, the enzyme also exhibits a great tendency to aggregate at lower concentrations of $\mathrm{GnHCl}$ or a high concentration of salt (Edwin and Jagannadham, 2000). Papain apart from being most studied plant cysteine proteases, further researches in understanding the specificity, the structural the effect brought by inhibitors, low $\mathrm{pH}$, metal ions and fluorinated alcohols has been identified as of critical importance (Huet et al., 2006; Naeem et al., 2006). Figure 2 shows the structure of papain from Molecular Modeling Database (MMDB), the structure is shown with all- $\alpha$ domain and an antparallel $\beta$-sheet domain. 


\subsection{Hydrophobicity of Papain}

It is often useful to examine the relative hydrophobicity or hydrophilicity values of the amino acids in a protein sequence. Since hydrophobic residues tend to be more buried in the interior of the molecule and hydrophilic residues are more exposed to solvent, a profile of these values can indicate the overall folding pattern. The hydrophobic interactions have the major influence in protein conformation and the most hydrophobic of the amino acid side chains are those of alanine, Valine, leucine, methionine and Isoleucine which vary in degrees of hydrophobic. The hydrophobic -hydrophilic interaction of papain amino acids in the side chain seems to be the major thermodynamic forces which drive protein folding. Investigation of the formation of the intermediate state of papain through inducing n-alkyl sulfates including sodium octyl sulfate, SOS; sodium decyl sulfate, SDeS; and sodium dodecyl sulfate, SDS at different concentrations has exhibited that hydrophobic interactions play an important role in inducing the two different intermediates along the two various thermodynamic pathways (Chamani et al., 2009). Catalytic activity of papain involves hydrolysis of proteins with broad specificity for peptide bonds, but preference for an amino acid bearing a large hydrophobic side chain at the P2 position while does not accept Val in P1 (Kamphuis et al., 1985). The enzyme has been reported to be generally more stable in hydrophobic solvents and at lower water contents and can catalyze reactions under a variety of conditions in organic solvents with its substrate specificity little changed from that in aqueous media (Stevenson and Storer, 1991). In general, native proteins have a hydrophobic core and a charged and/or polar group on the surface. The hydrophobic core helps to stabilize the tertiary structure of the protein by hydrophobic interaction while the outer polar surfaces preferentially interact with the exterior aqueous medium (Wang et al., 2006). Figure 3 shows hydrophobic amino acid of papain in space fill model.

Hyrophobicity of papain using carbon distribution profile along the sequence of papain is shown in Fig. 4. The graph indicates that carbon content is maintained at $31.45 \%$ of carbon all along the sequence. Some regions along the sequences have values above $31.45 \%$, these are considered to be higher hydrophobic regions as it has previously been reported when using carbon content distribution profile (Rajasekaran and Vijayasarathy, 2011). Thus, the overall hydrophobicity of papain enzyme being maintained at $31.45 \%$ of carbon all along the sequence contribute to stability of protein as previous been reported that stable and ordered proteins maintain $31.45 \%$ of carbon all along the sequence (Jayaraj et al., 2009).

\subsection{Mechanism, Biological Importance and Functions}

\subsection{Mechanism of Functions}

The mechanism in which the function of papain is made possible is through the cysteine- 25 portion of the triad in the active site that attacks the carbonyl carbon in the backbone of the peptide chain freeing the amino terminal portion. As this occurs throughout the peptide chains of the protein, the protein breaks apart. The mechanism by which it breaks peptide bonds involves deprotonation of Cys-25 by His-159. Asparagine- 175 helps to orient the imidazole ring of His-159 to allow this deprotonation to take place. Although far apart within the chain, these three amino acids are in close proximity due to the folding structure. It is though these three amino acids working together in the active site that provides this enzyme with its unique functions. Cys-25 then performs a nucleophilic attack on the carbonyl carbon of a peptide backbone (Menard et al., 1990; Tsuge et al., 1999). In the active site of papain, Cys -25 and His -159 are thought to be catalytically active as a thiolate-imidazolium ion pair. Papain can be efficiently inhibited by peptidyl or non-peptidyl N-nitrosoanilines (Guo et al., 1996; 1998). The inactivation is due to the formation of a stable S-NO bond in the active site $(S$ nitroso-Cys ${ }^{25}$ ) of papain (Xian et al., 2000).

\subsection{Papain in Medical Uses}

Papain acts as a debris-removing agent, with no harmful effect on sound tissues because of the enzyme's specificity, acting only on the tissues, which lack the $\alpha 1$ antitripsine plasmatic antiprotease that inhibits proteolysis in healthy tissues (Flindt, 1979). The mechanism of biochemical removal of caries involves cleavage of polypeptide chains and/or hydrolysis of collagen crosslinkages. These cross-linkages give stability to the collagen fibrils, which become weaker and thus more prone to be removed when exposed to the papain gel (Beeley et al., 2000). Papain-based gel has also been reported as a potential useful in biochemical excavation procedures for dentin (Piva et al., 2008). Papain has advantages for being used for chemomechanical dental caries removal since it does not interfere in the bond strength of restorative materials to dentin (Lopes et al., 2007).

Papain enzyme has a long history of being used to treat sports injuries, other causes of trauma and allergies (Dietrich, 1965). Fortunately papain has a proven track record in managing all of these conditions with clinical evidence of significant benefits for use of papain protease enzyme in cases of sports injury. 


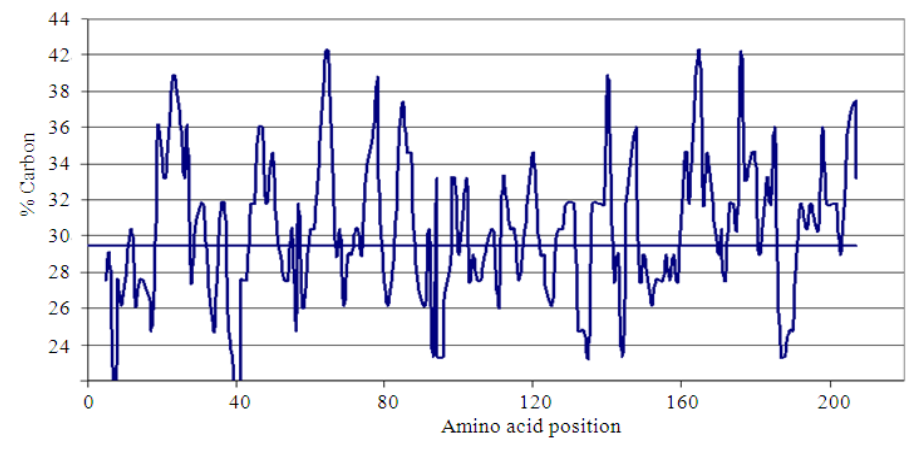

Fig. 4. Carbon distribution profile along the sequence of papain (1CVZ)

It has previously been reported that minor injuries healed faster with papain proteases than with placebos. Furthermore, athletes using papain protease supplements were able to cut recovery time from 8.4 days to 3.9 days (Trickett, 1964; Dietrich, 1965). Papain also has been successfully used to overcome the allergies associated with leaky gut syndrome, hypochlorhydria (insufficient stomach acid) and intestinal symbiosis like gluten intolerance. Papain has previously been reported to have significant analgesic and anti-inflammatory activity against symptoms of acute allergic sinusitis like headache and toothache pain without side effects (Mansfield et al., 1985).

\subsection{Papain Uses in Drug Design}

Papain shares many features with physiologically important mammalian cysteine proteases and show nearly identical folding patterns especially around the active site which has been useful for drug design (Meara and Rich, 1996). The X-ray coordinate system for papain solved at 1.7 A resolutions is a representative example of the structure of a covalent ligand-bound cysteine protease complex particularly in the papain superfamily (Tsuge et al., 1999). Thus, papain is reported to be useful as an experimental model structure to understand the inhibition mechanism of newly developed specific inhibitors of cathepsin L, the papain superfamily and its an antioxidant properties can be useful in preventing certain types of illnesses (Tsuge et al., 1999; Gayosso-Garcia et al., 2010). Since most of the amino acid residues that are involved in the binding to papain are conserved in cathepsin $\mathrm{L}$, this publicly available high resolution structure has provided an excellent model for the successful design of highly active and specific cathepsin L inhibitors (Katunuma et al., 1999). Papain is also reported to be used as a surrogate enzyme in a drug design effort to obtain potent and selective inhibitors of cathepsin $\mathrm{K}$, a new member of the papain superfamily of cysteine proteases that is selected and highly expressed in osteoclasts (LaLonde et al., 1998). Papain is also reported to be useful as catalyzed (co) oligomerization of $\alpha$-amino acids (Schwab et al., 2012).

\subsection{Industrial Uses and Pharmaceutical Preparations}

Papain is used in meat tenderizers; the major meat proteins responsible for tenderness are the myofibrillar proteins and the connective tissue proteins. Protease enzymes are used to modify these proteins and papain has been extensively used as a common ingredient in the brewery and in the meat and meat processing (Khanna and Panda, 2007). Papain importance as tenderizers in the food industry is similar to collagenases, which have application in the fur and hide tanning to ensure uniform dying of leather. Papain also can act as a clarifying agent in many food industry processes. As a protein digestant, papain is used in combating dyspepsia and other digestive disorders and disturbances of the gastrointestinal tract (Huet et al., 2006). Papain has for quite a long time been used in pharmaceutical preparations of diverse food manufacturing applications as the production of high quality kunafa and other popular local sweets and pastries. Papain has been reported to improve meltability and stretchability of Nabulsi cheese with outstanding fibrous structure enhancing superiority in the application in kunafa, pizza and pastries (Abu-Alruz et al., 2009). Also as pharmaceutical products in gel based a proteolytic cisteine enzyme, papain presents antifungal, antibacterial and anti-inflammatory properties (Chukwuemeka and Anthoni, 2010).

\subsection{Potential for Production and Market Opportunities}

Papain enzyme is extracted from Carica papaya which is a tropical and a herbaceous succulent plant that possess self supporting stems which grows in all tropical countries and many sub-tropical regions of the world (Jaime et al., 2007). Moreover, there is no limitation due to seasonality as the papaya is available almost round the 
year. Consequently, there is a need to facilitate the entrepreneurs in understanding the potential of papaya production and the importance of setting up a unit of papain. A well managed papaya production has recorded higher papain yield of $8.17 \mathrm{~g}$ per fruit and highest papain of $686.29 \mathrm{~g}$ per plant in a period of 6 months (Kamalkumar et al., 2007; Reddy et al., 2012). Papain is used in many industries such as breweries, pharmaceuticals, food, leather, detergents, meat and fish processing for a variety of processes. Therefore, the end use segments are many in signifying that papain has high export demand. Since there are good prospects for papain market, the papaya production and extraction of papain can be a high source of income even for small farmers.

\section{CONCLUSION}

Papain has revealed to be an enzymatic protein of significant biological and economic importance. It is through the unique structure of papain that provides functionality and helps explain how this proteolytic enzyme works and also makes it valuable for a variety of purposes. Further researches on papain enzyme in understand the specificity, the structural the effect brought various thermodynamic pathways is of critical importance. Papain is found naturally in papaya which is a versatile plant having number of uses and enzymatic properties. Since the papaya grows in a wide range of climate, papaya production for extraction of papain can be a source of earning a high income to farmers.

\section{REFERENCES}

Abu-Alruz, K., A. S. Mazahreh, J. M. Quasem, R. K. Hejazin and J. M. El-Qudah, 2009. Effect of Proteases on Meltability and Stretchability of Nabulsi Cheese. Am. J. Agric. Biol. Sci., 4: 173178. DOI: 10.3844 /ajabssp.2009.173.178

Beeley, J.A., H.K. Yip and A.G. Stevenson, 2000. Chemochemical caries removal: A review of the techniques and latest developments. Br. Dent. J. 188: 427-30.

Chamani, J., M. Heshmati, O. Rajabi and K. Parivar, 2009. Thermodynamic study of intermediate state of papain induced by n-alkyl sulfates at two different ph values: A spectroscopic approach. Open Sur. Sci. J., 1: 20-29.

Chukwuemeka, N.O. and A.B. Anthoni, 2010. Antifungal effects of pawpaw seed extracts and papain on post harvest Carica papaya L. fruit rot. Afri. J. Agri. Res., 5: 1531-1535.
Cohen, L.W., V.M. Coghlan and L.C. Dihel, 1986. Cloning and sequencing of papain-encoding cDNA. Gene, 48: 219-227. DOI: 10.1016/0378-1119(86)90080-6

Dietrich, R.E., 1965. Oral proteolytic enzymes in the treatment of athletic injuries: a double-blind study. Pennsyl. Med. J., 68: 35-37. PMID: 5318158

Edwin, F. and M.V. Jagannadham, 2000. Single disulfide bond reduced papain exists in a compact intermediate state. Biochem. Biophys. Acta., 1479: 69-82. DOI: 10.1016/S0167-4838(00)00062-5

Edwin, F., Sharma and M.V. Jagannadham, 2002. Single disulfide bond reduced papain exists in a compact intermediate state. Biochem. Biophys. Res. Commun. 1479: 69-82. DOI: 10.1016/S0167-4838(00)00062-5

Flindt, M.L., 1979. Allergy to alpha-amylase and papain. Lancet, 1: 1407-1408. PMID: 87867

Gayosso-Garcia, L.E., M.E. Yahia, M.A. Martínez-Téllez and A.G. González-Aguilar, 2010. Effect of maturity stage of papaya maradol on physiological and biochemical parameters. Am. J. Agric. Biol. Sci., 5: 194-203. DOI: 10.3844/ajabssp.2010.194.203

Ghosh, S., 2005. Physicochemical and conformational studies of papain/sodium dodecyl sulfate system in aqueous medium. J. Colloid Surf. A: Phys. Eng. Aspects, 264: 6-16. DOI: 10.1016/j.colsurfa.2005.02.032

Guo, Z., A. McGill, L. Yu, J. Li and J. Ramirez et al., 1996. ChemInform abstract: S-Nitrosation of proteins by Nmethyl-N-nitrosoanilines. ChemInform. DOI: 10.1002/chin. 199628113

Guo, Z., J. Ramirez, J. Li and P.G.Wang, 1998. Peptidyl Nnitrosoanilines: A novel class of cysteine protease inactivators. J. Am. Chem. Soc., 120: 3726-3734. DOI: 10.1021/ja974187e

Jaime, A., S. Teixeira Da, R. Zinia, T.N. Duong and S. Dharini et al., 2007. Papaya (Carica papaya L.) Biology and biotechnology. Tree Forest. Sci. Biotechnol., 1: 47-73.

Jayaraj, V., R. Suhanya, M. Vijayasarathy, M. Anandagopu and P. Anandagopu, 2009. Role of large hydrophobic residues in proteins. Bioinformation, 3: 409-412. PMID: 19759817

Kamalkumar, R., R. Amutha, S. Muthulaksmi, P. Mareeswari and W.B. Rani, 2007. Screening of Dioecious Papaya Hybrids for Papain Yield and Enzyme Activity. Res. J. Agric. Biol. Sci., 3: 447-449.

Kamphuis, I.G., K.H. Kalk, M.B. Swarte and J. Drenth, 1984. The structure of papain refined at $1.65 \mathrm{~A}$ resolution. J. Mol. Biol., 179: 233-256. DOI: 10.1016/0022-2836(84)90467-4 
Kamphuis, I.G., J. Drenth and E.N. Baker, 1985. Thiol proteases: Comparative studies based on the highresolution structures of papain and actinidin and an amino acid sequence information for cathepsins B and $\mathrm{H}$ and stem bromelain. J. Mol. Biol., 182: 317-329. DOI: $10.1016 / 0022-2836(85) 90348-1$

Katunuma, N., E. Murata, H. Kakegawa, A. Matsui and H. Tsuzuki et al., 1999. Structure based development of novel specific inhibitors for cathepsin $L$ and cathepsin $\mathrm{S}$ in vitro and in vivo. FEBS Lett., 458: 6-10. PMID: 10518923

Khanna, N. and P.C. Panda, 2007. The effect of papain on tenderization and functional properties of spending hen meat cuts. Indian J. Anim. Res., 41: 55-58.

LaLonde, J.M., B. Zhao, W.W. Smith, C.A. Janson and R.L. DesJarlais et al., 1998. Use of papain as a model for the structure-based design of cathepsin K inhibitors: crystal structures of two papain-inhibitor complexes demonstrate binding to S'-subsites. J.Med.Chem., 41: 4567-4576. PMID: 9804696

Huet, J., Y. Looze, K. Bartik, V. Raussens and R. Wintjens et al., 2006. Structural characterization of the papaya cysteine proteinases at low $\mathrm{pH}$. Biochem. Biophysical Res. Commun., 341: 620-626. PMID: 16434027

Lopes, M.C., R.C. Mascarini, B.M. de Silva, F.M. Florio and R.T. Basting, 2007. Effect of a papain-based gel for chemomechanical caries removal on dentin shear bond strength. J. Dent. Child (Chic), 74: 93-97. PMID: 18477426

Madej, T., K.J. Addess, J.H. Fong, L.Y. Geer and R.C. Geer et al., 2012. MMDB: 3D structures and macromolecular interactions. Nucleic Acids Res., 40: D461-D464. DOI: 10.1093/nar/gkr1162

Mansfield, L.E., S. Ting, R.W. Haverly and T.J. Yoo, 1985. The incidence and clinical implications of hypersensitivity to papain in an allergic population, confirmed by blinded oral challenge. Ann. Allergy., 55: 541-543. PMID: 4051260

Meara, J.P. and D.H. Rich, 1996. Mechanistic studies on the inactivation of papain by epoxysuccinyl inhibitors. J. Med. Chem., 39: 3357-3366. PMID: 8765519

Menard, R., H.E. Khouri, C. Plouffe, R. Dupras and D. Ripoll et al., 1990. A protein engineering study of the role of aspartate 158 in the catalytic mechanism of papain. Biochemistry, 29: 6706-6713. DOI: 10.1021/bi00480a021

Mitchel, R.E., M.I. Claiken and E.L.J. Smith, 1970. The complete amino acid sequence of papain. J. Biol. Chem., 245: 3485-3492. PMID: 5470818
Naeem, A., S. Fatima and S.K. Khan, 2006. Characterization of partially folded intermediates of papain in the presence of cationic, anionic and nonionic detergents at low $\mathrm{pH}$. Biopolymers, 83: 1-10. DOI: 10.1002/bip. 20520

Piva, E., F.A. Ogliari, R.R.D. Moraes, F. Cora and S. Henn et al., 2008. Papain-based gel for biochemical caries removal: Influence on microtensile bond strength to dentin. Braz. Oral. Res., 22: 364-370. PMID: 19148394

Rajasekaran, E. and M. Vijayasarathy, 2011. CARBANA: Carbon analysis program of protein sequences. Bioinformation, 5: 455-457. PMID: 21423892

Reddy, S.R., R.B. Krishna and K.J. Reddy, 2012. Sex determination of Papaya (Carica papaya) at seedling stage through RAPD Markers. Res. Biot., 3: 21-28.

Robert, AM., L. Dann and G. Lown, 1974. The specificity of the $\mathrm{S}_{1}$ subsite of papain. J. Biochem., 141: 495-501. PMID: 4455218

Schwab, W.L., M.J.W. Kloosterman, J. Konieczny and K. Loos, 2012. Papain Catalyzed (co) Oligomerization of $\alpha$-Amino Acids. Polymers, 4: 710-740. DOI: 10.3390/polym4010710

Stevenson, E.D. and C.A. Storer, 1991. Papain in organic solvents: Determination of conditions suitable for biocatalysis and the effect on substrate specificity and inhibition. Biotechnol. Bioeng., 37: 519-527. PMID: 18600639

Trickett, P., 1964. Proteolytic enzymes in treatment of athletic injuries. Applied Ther., 6:647-652. PMID: 14195254

Tsuge, H., T. Nishimura, Y. Tada, T. Asao and D. Turk et al., 1999. Inhibition mechanism of cathepsin L-specific inhibitors based on the crystal structure of papainCLIK148 complex. Biochem. Biophys. Res. Commun., 266: 411-416. DOI: 10.1006/bbrc. 1999.1830

Uhlig, H., 1998. Industrial Enzymes and their Applications. 1 st Edn., John Wiley and Sons, New York, ISBN-10: 0471196606, pp: 454.

Wang, L.J., N. Sun, S. Terzyan, X.J. Zhang and D.R. Benson, 2006. A histidine/tryptophan $\pi$-stacking interaction stabilizes the heme-independent folding core of microsomal apocytochrome b5 relative to that of mitochondrial apocytochrome b5. Biochemistry, 45: 13750-13759. DOI: 10.1021/bi0615689

Xian, M., X. Chen, Z. Liu, K. Wang and P.G. Wang, 2000. Inhibition of papain by $s$-nitrosothiols. J. Biol. Chem., 275: 20467-20473. DOI: 10.1074/jbc.M001054200 